\title{
Involvement of Serotonergic System and Magnesium on Anxiolytic Effects of Pomegranate in Male Mice
}

\author{
Mahsa Hadipour Jahromy*, Azadeh Shariatifar, \\ Somaye Samiee, Melica Vaziri, Maryam Bagheri Shahraki, \\ Shirin Mansoori Dara \\ Department of Pharmacology, Medical Sciences Research Center, Faculty of Medicine, Islamic Azad University, \\ Tehran Medical Sciences Branch, Tehran, Iran \\ Email: *jahromymh@yahoo.com
}

Received 28 May 2014; revised 28 June 2014; accepted 10 July 2014

Copyright (C) 2014 by authors and Scientific Research Publishing Inc.

This work is licensed under the Creative Commons Attribution International License (CC BY).

http://creativecommons.org/licenses/by/4.0/

(c) (i) Open Access

\section{Abstract}

The anxiolytic activities of Punica granatum $L$. fruit juice (PGFJ) in various validated animal models of anxiety and amnesia have been recently reported in mice. Similarly, anxiolytic-like activity of magnesium chloride has been exhibited in the elevated plus-maze test in mice, in some studies. Buspirone is an anxiolytic psychoactive drug with known effects on 5-HT HA $_{1 \mathrm{~A}}$ receptors that its action is not related to benzodiazepines. The purpose of the present study was to examine interactions between PGFJ, magnesium (Mg) and buspirone as a partial agonist of $5-\mathrm{HT}_{1 \mathrm{~A}}$ receptors in producing anxiolytic-like activity in the elevated plus maze in mice. The anxiolytic-like effect of PGFJ (5, 10 and $20 \mathrm{ml} / \mathrm{kg}$, orally), buspirone $(5 \mathrm{mg} / \mathrm{kg}$, i.p), $\mathrm{Mg} \mathrm{(50} \mathrm{mg/kg,} \mathrm{orally)} \mathrm{and} \mathrm{their} \mathrm{inte-}$ ractions were evaluated after ten days' treatment. PGFJ given at all doses induced an anxiolyticlike effect significantly increasing the percentage of the time spent in the open arms, and the percentage of the open arm entries, in a dose-dependent manner. Buspirone showed anxiolytic effect after ten days; however, its effect was roughly comparable to the effect of PGFJ $5 \mathrm{ml} / \mathrm{kg}$. Buspirone in combination with PGFJ ( $5 \mathrm{ml} / \mathrm{kg}$ ), did produce more effect compared to buspirone alone and nearly in the range of PGFJ $5 \mathrm{ml} / \mathrm{kg}$ response. Also, Mg induced an anxiolytic-like effect that was more than effects observed by buspirone $5 \mathrm{mg} / \mathrm{kg}$. However, binary application of buspirone and Mg showed anxiolytic effects more than buspirone, alone. In another group, $\mathrm{Mg}$ in combination with PGFJ (5 ml/kg), produced more anxyolitic effects compared to either Mg or PEF alone. It can be concluded that Pomegranate anxyolitic-like effect is dependent on interactions with both GABAergic (related to $\mathrm{Mg}$ ) and serotonergic $\left(5-\mathrm{HT}_{1 \mathrm{~A}}\right)$ systems.

\footnotetext{
${ }^{*}$ Corresponding author.
} 


\section{Keywords}

\section{Anxiety, Pomegranate, Magnesium Chloride, Buspirone, Mice}

\section{Introduction}

Anxiety is a normal human emotion that everyone experiences at times. Many people feel anxious, or nervous, when faced with a problem. Anxiety disorders, however, are different. They can cause such distress that it interferes with a person's ability to lead a normal life. An anxiety disorder is a serious mental illness. For people with anxiety disorders, worry and fear are constant and can be crippling [1] [2].

In recent years, interest is growing in alternative medicines that include plant derived medications, supplements and poly formulations that affect the mind. In our country, many herbal medicines and supplements have been accepted for treating anxiety disorders.

Punica granatum is one such medicinal plant that has been extensively used in the traditional medicine. The pomegranate, Punica granatum L., has a wide range of therapeutic effects that may be attributed to antioxidant, anticarcinogenic, and anti-inflammatory mechanisms. Clinical applications of various extract (peel, bark, fruit, seed, pulp, and flower) of pomegranate have focusing on treatment and prevention of cancer, cardiovascular disease, diabetes and bacterial infections [3].

Magnesium (Mg) which is available as supplement for some neurological disorders is an essential intracellular bioelement. It plays an important role in a wide variety of metabolic reactions, in particular energy-requiring processes [4]. In the central nervous system (CNS) it is involved in signal transmission. Several studies have demonstrated that acute and chronic administration of Mg reduces immobility time in the forced swimming test (FST) in mice and rats, and enhances the anti-immobility activity of imipramine in this model [5]-[7].

Nowadays, selective serotonin reuptake inhibitors, the drugs most commonly used to treat depression, are frequently considered as a first line treatment for anxiety disorders [8].

Buspirone functions as a serotonin 5- $\mathrm{HT}_{1 \mathrm{~A}}$ receptor partial agonist. This action is thought to mediate its anxiolytic and antidepressant effects [9]. Buspirone's efficacy is comparable to that of members of the benzodiazepine family in treating anxiety disorder, although it tends to have a delayed onset of action. It may take several weeks before buspirone's anxiolytic effects become noticeable [10]-[12].

Recently, an indication that the serotoninergic system is involved in the antidepressant-like effect of $\mathrm{Mg}$ was given by the fact that the pre-treatment of mice with an inhibitor of serotonin synthesis, p-chlorophenylalanine was able to reduce the anti-immobility effect of magnesium in the FST [13] [14]. In recent studies, anxiolytic effecs of some herbal medicines and their interactions with serotnergic system are conducted.

Therefore, it is important to investigate the involvement of $\mathrm{Mg}$ and serotonergic neurotransmission in the mechanism of anxiolytic actions of pomegranate. In this study, we investigated the interaction between $\mathrm{Mg}$ and commonly accepted anxyolitic drug, buspirone as a partial agonist of 5- $\mathrm{HT}_{1 \mathrm{~A}}$ receptors, with anxiolytic-like activity of pomegranate in the elevated plus maze in mice.

\section{Materials and Methods}

\subsection{Pomegranate Extract Preparation}

Pomegranates (Punica granatum L.) fruits, were collected by one of the colleagues from the agriculture garden, in Saveh, where known to have one of the best pomegranate native in Iran. Then washed, chilled to $4^{\circ} \mathrm{C}$, and stored. The seeds of the fruit containing the intact juice sacs were manually separated from the pericarp, and the whole pomegranate fruit juice extracted (PGFJ) by the aid of electric juicer so that seeds break. Then filtered and stored in clean jars in fridge.

\subsection{Animals}

Sixty three male adult mice weighing $23 \pm 2 \mathrm{~g}$ (Pasteur Institute, Karaj Production and Research Center, Iran) were used in this study. The animals were randomly divided into nine groups of seven each and treated according to the experimental protocol for ten days. Animals housed under the following laboratory conditions: temperature 
$22^{\circ} \mathrm{C} \pm 1^{\circ} \mathrm{C}$, humidity $40 \%-60 \%, 12 \mathrm{~h} \mathrm{Light/Dark} \mathrm{cycle,} \mathrm{lights} \mathrm{on} \mathrm{at} \mathrm{07:00} \mathrm{h.} \mathrm{Mice} \mathrm{were} \mathrm{maintained} \mathrm{in} \mathrm{polye-}$ thylene cages with enough food and water available ad libitum. All measurements were performed between 9:00 and 15:00 $\mathrm{h}$ in the animal testing room. Mice were treated by the current law of Medical Sciences Research Center, Tehran Medical Sciences Branch, Islamic Azad University, Tehran, Iran, in accordance with the National Institutes of Health (NIH) Guide for Care and Use of Laboratory Animals.

\subsection{Drugs and Experimental Protocol}

Mg (magnesium Chloride Hexahydrate 98\%, DAE JUNG, Korea), was administered at $50 \mathrm{mg} / \mathrm{kg} / \mathrm{day}$, orally, Buspiron (Iran-Darou) $5 \mathrm{mg} / \mathrm{kg}$, i.p and Pomegranate juice administered at 5, 10 and $20 \mathrm{ml} / \mathrm{kg} /$ day orally. Control Group received distilled water orally.

Based on our previous experiments conducted before, focusing on pomegranate anxiolytic effects, we decided first to reveal different grouping interactions and then in another experimental design, we will explore to uncover the underlying mechanism of action.

Grouping: Group 1: Control, received distilled water orally; Group 2, 3 and 4: PGFJ at 5, 10 and $20 \mathrm{ml} / \mathrm{kg}$, respectively; Group 5 Buspirone 5 mg/kg; Group 6: Mg 50 mg/kg; Group 7: PGFJ 5 ml/kg + Buspiron 5 mg/kg; Group 8: PGFJ 5 ml/kg + Mg 50 mg/kg; Group 9: Buspirone 5 mg/kg + Mg 50 mg/kg.

The studies were carried out on mice according to the method of Lister [15]. The plus-maze apparatus was made of Plexiglas and consisted of two open $(30 \times 5 \mathrm{~cm})$ and two closed $(30 \times 5 \times 15 \mathrm{~cm})$ arms. The arms extended from a central platform of $5 \times 5 \mathrm{~cm}$. The apparatus was mounted on a Plexiglas base raising it $38.5 \mathrm{~cm}$ above the floor. The test consisted in placing a mouse in the center of the apparatus (facing a closed arm) and allowing it to freely explore. The number of entries into the open arms and the time spent in these arms were scored for a 5-min test period. An entry was defined as placing all four paws within the boundaries of the arm. The following measures were obtained from the test: the total number of arm entries; the percentage of arm entries into the open arms; the time spent in the open arms expressed as a percentage of the time spent in both the open and closed arms. Anxiolytic activity was indicated by increases in time spent in open arms or in number of open arm entries.

All values were expressed as mean \pm SEM from seven animals. The results were subjected to statistical analysis by using Unpaired-t test to calculate the significance difference if any among the groups. $\mathrm{P}<0.05$ was considered significant.

\section{Results}

All data has been compared and shown in Figure 1 \& Figure 2. PGFJ given at all doses (5, 10 and $20 \mathrm{ml} / \mathrm{kg})$ induced anxiolytic-like effects significantly increasing the percentage of the time spent in the open arms (Figure 1), and the percentage of the open arm entries (Figure 2). The increase in the percentage of the time spent in the open arms and the percentage of the open arm entries induced by $20 \mathrm{mLg} / \mathrm{kg}$ was highest when compared to other PGFJ amounts. Buspirone (5 mg/kg) showed anxiolytic effect after ten days, however, its effect on both percent time spend in open arms the percentage of the open arm entries, were lower than PGFJ $10 \mathrm{ml} / \mathrm{kg}$, while roughly comparable to the effect of PGFJ $5 \mathrm{ml} / \mathrm{kg}$. Buspirone in combination with PGFJ ( $5 \mathrm{ml} / \mathrm{kg}$ ), did produce more effect compared to buspirone alone and nearly in the range of PGFJ $5 \mathrm{ml} / \mathrm{kg}$ response.

$\mathrm{Mg}$ given at a dose of $50 \mathrm{mg} / \mathrm{kg}$ for ten days induced an anxiolytic-like effect significantly increasing the percentage of the open arm entries. The increase was more than effects observed by buspirone $5 \mathrm{mg} / \mathrm{kg}$. However, binary application of buspirone (5 mg/ $/ \mathrm{kg})$ and $\mathrm{Mg}(50 \mathrm{mg} / \mathrm{kg})$ showed anxiolytic effects significantly more than buspirone, alone, and somehow Mg (50 mg/kg) effect, preserved.

In another group, Mg $50 \mathrm{mg} / \mathrm{kg}$ in combination with PGFJ (5 ml/kg), did produce more anxyolitic effects compared to either Mg or PEF alone. It means that the percentage of time spent in open arms and open arm entries increased significantly.

\section{Discussion}

It is reported that Punica granatum fruit juice possesses significant anxiolytic effects that could be due to the presence of various phytochemicals such as flavonoids, saponins and tannins. However, its mechanism of action needed to be investigated, although a preliminary research compared its anxiolytic action with diazepam [16]. 


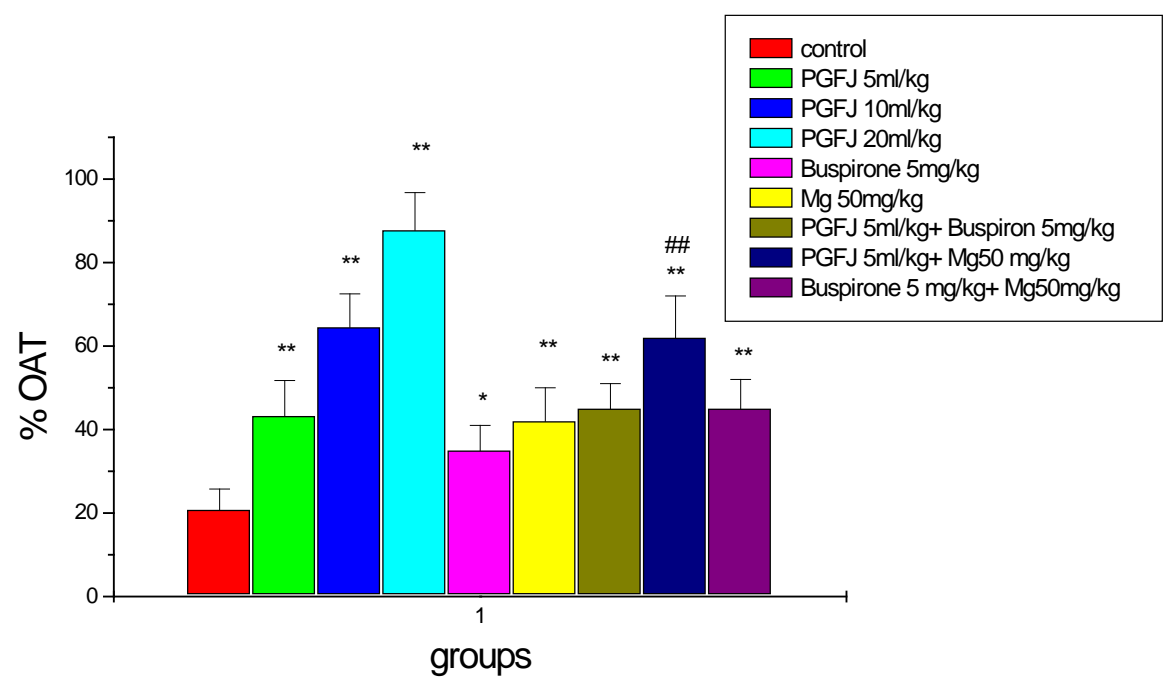

Figure 1. Percentage of time spent in open arms for PGFJ, Buspirone, Mg and their combination in the elevated plus-maze procedure in mice (The values represent the means \pm SEM (n = 7). * $\mathrm{p}<0.05,{ }^{* *} \mathrm{p}<0.01$ compared to control. \# compared to PGFJ $5 \mathrm{ml} / \mathrm{kg}$.

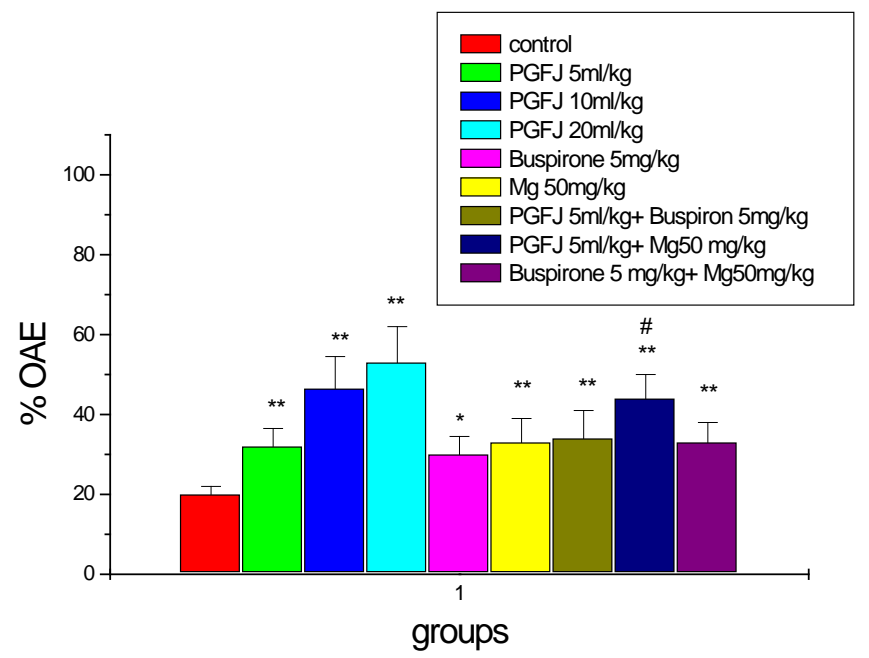

Figure 2. Percentage of open arm entries for PGFJ, Buspirone, Mg and their combination in the elevated plus-maze procedure in mice (The values represent the means \pm SEM $(n=7)$. ${ }^{*} \mathrm{p}<0.05,{ }^{* *} \mathrm{p}<$ 0.01 compared to control. \# compared to PGFJ $5 \mathrm{ml} / \mathrm{kg}$.

In this study, the interaction of commonly accepted anxiolytic drug, buspirone as a partial agonist of 5- $\mathrm{HT}_{1 \mathrm{~A}}$ receptors and $\mathrm{Mg}$, as a supplement known with anxiolytic effects mainly related to GABA, were evaluated with anxiolytic-like activity of pomegranate in the elevated plus maze in mice.

Animal behavioral models of anxiety have played an important role in the assessment of anxiolytics. Choice of the animal models for anxiety studies and to search for new classes of anxiolytic compounds with potential therapeutic applications is an important parameter in drug development research.

EPM assay essentially determines a preference between a comparatively safe and comfortable environment (the closed arms) and a risky environment (elevated open spaces). This is often discussed in terms of avoidance or fear, which is technically a preference test-one portion of the arm is avoided only in comparison to the other portion. The general principle is that the more "anxious" the subjects are, the less likely they will be to explore an uncomfortable, risky, or threatening environment. Thus, previous stress, presence of a predator odor, previous handling, manipulation of stress hormones and peptides all effect behavior in the EPM. Validation of the 
EPM has been established in locomotors and anxiety, stressors increase anxiety-like behavior, behavior in other anxiety tests. Other tests such as open field test and hole board may also use to predict hyperactivity and anxiety behavior.

Benzodiazepines, the widely prescribed and clinically effective anxiolytics, produce their pharmacological actions via specific high affinity binding sites on GABA-A receptor. At the cellular level, stimulation of GABA-A receptor results in an increased chloride conductance and usually hyperpolarisation [4].

Buspirone, is an anxiolytic psychoactive drug of the azapirone chemical class. It is primarily used to treat generalized anxiety disorder (GAD). Unlike most drugs predominately used to treat anxiety, buspirone's pharmacology is not related to benzodiazepines or barbiturates, and so does not carry the risk of withdrawal symptoms when discontinued [5].

Buspirone functions as a serotonin 5-HT1A receptor partial agonist. This action is thought to mediate its anxiolytic and antidepressant effects. Additionally, it functions as a presynaptic dopamine antagonist at the D2, D3 and D4 [9] receptors. Buspirone is also a partial $\alpha 1$ receptor agonist. The ability of buspirone to selectively block presynaptic mesolimbic D2 autoreceptors in lower doses appears to result in increased dopamine synthesis and release [11]. Effects of 5- $\mathrm{HT}_{1 \mathrm{~A}}$ receptor agonist and NMDA receptor antagonist in the social interaction test and the elevated plus maze have been tested [17].

Some evidence showed that anxiolytic-like activity of Mg in EPM test involves GABAergic neurotransmission and indicated that benzodiazepine receptors are involved in the anxiolytic-like effects of $\mathrm{Mg}$ [18].

It is reported the administration of magnesium salts produces an antidepressant-like effect in the FST, a widely-accepted behavioral model predictive of antidepressant activity that is sensitive to all major classes of antidepressant drugs including tricyclics, serotonin-specific reuptake inhibitors, monoamine oxidase inhibitors and atypicals. Of most importance, results clearly demonstrated the involvement of the monoaminergic system in the antidepressant-like effect of $\mathrm{MgCl}_{2}$ in the FST and also, the synergistic antidepressant-like effect of $\mathrm{MgCl}_{2}$ administration with antidepressants from different classes: fluoxetine, imipramine or bupropion. Interaction of imipramine, citalopram, reboxetine and tianeptine with $\mathrm{Mg}^{2+}$ was also examined and a synergistic antidepressant-like effect of $\mathrm{Mg}^{2+}$ was shown only with imipramine, citalopram and tianeptine [5]-[8]. Therefore interaction of $\mathrm{Mg}$ with serotonergic system seems to be important and need for consideration in order to predict their net effect in combinations used.

In our results, anxiolytic effects of pomegranate enhanced when co administered with $\mathrm{Mg}$.

This apparent synergism was manifested as a significantly increased time spent in open arms and the number of open arm entries. Due to some reports, Mg mostly modify GABA-ergic neurotransmission [19], thus, anxiolyticlike effects of Pomegranate seems to be mediated, at least in part, through an interaction with GABAA system.

In the present study, the involvement of $5-\mathrm{HT}_{1 \mathrm{~A}}$ receptors in the anxiolytic-like effect of $\mathrm{Mg}$ and pomegranate was indicated by the results showing that treatment of mice with buspirone did not produce more anxiolytic effect in the EPM test. From the pharmacological point of view, this might be attributed to competitive action on the same receptor, regarding buspirone as a partial agonist of serotonergic system. However, the selective $5-\mathrm{HT}_{1 \mathrm{~A}}$ receptor antagonist or other full agonists should be tested to conduct more study. Overall, this experiment partly indicates that the $5-\mathrm{HT}_{1 \mathrm{~A}}$ receptor could be relevant for the anxiolytic action of both $\mathrm{Mg}$ and Pomegranate in the EPM test.

\section{Conclusions}

The present study extends literature data about mechanisms underlying the anxiolytic-like effect of pmegranate in the EPM test. We have shown that its anxyolitic-like effect is partly dependent on its interaction with the Mg and serotonergic $\left(5-\mathrm{HT}_{1 \mathrm{~A}}\right)$ systems.

Since therapeutic effects of Punica granatum may be attributed to antioxidant, anticarcinogenic, and antiinflammatory mechanisms, the combination medication of Punica granatum and either Magnesium or Buspirone offered better effects which can make the conclusion that the anxyolitic-like effect of Pomegranateis is dependent on interactions with both GABAergic (related to Mg) and serotonergic (5-HT1A) systems.

In fact, other mechanisms could be possibly the involvement of both GABAergic and serotonergic system in the mechanism of the anxiolytic-like action of pomegranate. Of course, more study needed to be designed using specific antagonists to reveal exact interactions. 


\section{Acknowledgements}

The research was supported by the grant (No. 43335) from the Research Deputy of Islamic Azad University, Tehran Medical Sciences Branch, Tehran, Iran. Authors would like to thank Dr Ghorbani Yekta, Dr M Riazi, Mr Shafikhani and Ms Hashemi for their help during experimental work.

\section{References}

[1] American Psychiatric Association (2013) Diagnostic and Statistical Manual of Mental Disorders. 5th Edition, American Psychiatric Publishing, Arlington, MA, 189-195.

[2] Patel, G. and Fancher, T.L. (2013) In the Clinic. Generalized Anxiety Disorder. Annals of Internal Medicine, 159, Article ID: ITC6-1. http://dx.doi.org/10.7326/0003-4819-159-11-201312030-01006

[3] Jurenka, J. (2008) Therapeutic Applications of Pomegranate (Punica granatum L.): A Review. Alternative Medicine Review, 13, 128-144.

[4] Lydiard, R.B. (2003) The Role of GABA in Anxiety Disorders. The Journal of Clinical Psychiatry, 64, 21-27.

[5] Ryan, M.F. (1991) The Role of Magnesium in Clinical Biochemistry: An Overview. Annals of Clinical Biochemistry, 28, 19-26. http://dx.doi.org/10.1177/000456329102800103

[6] Cardoso, C.C., Lobato, K.R., Binfaré, R.W., Ferreira, P.K., Rosa, A.O., Santos, A.R.S. and Rodrigues, A.L.S. (2009) Evidence for the Involvement of the Monoaminergic System in the Antidepressant-Like Effect of Magnesium. Progress in Neuro-Psychopharmacology \& Biological Psychiatry, 33, 235-242. http://dx.doi.org/10.1016/j.pnpbp.2008.11.007

[7] Poleszak, E., Szewczyk, B., Kêdzierska, E., Wlaź, P., Pilc, A. and Nowak, G. (2004) Antidepressant- and AnxiolyticLike Activity of Magnesium in Mice. Pharmacology Biochemistry and Behavior, 78, 7-12. http://dx.doi.org/10.1016/j.pbb.2004.01.006

[8] Poleszak, E., Wlaź, P, Kêdzierska, E., Nieoczym, D., Wyska, E., Szymura-Oleksiak, J., Fidecka, S., et al. (2006) Immobility Stress Induces Depression-Like Behavior in the Forced Swim Test in Mice: Effect of Magnesium and Imipramine. Pharmacological Reports, 58, 746-752.

[9] Dunlop, B.W. and Davis, P.G. (2008) Combination Treatment with Benzodiazepines and SSRIs for Comorbid Anxiety and Depression: A Review. Prim Care Companion Journal of Clinical Psychiatry, 10, 222-228. http://dx.doi.org/10.4088/PCC.v10n0307

[10] Fulton, B. and Brogden, R.N. (1997) Buspirone. CNS Drugs, 7, 68-88. http://dx.doi.org/10.2165/00023210-199707010-00007

[11] Buspirone monoFigure. Retrieved 2011-08-27. www.drugs.com/monograph/buspirone-hydrochloride.html

[12] Jadhav, S.A., Gaikwad, R.V., Gaonkar, R.K., Thorat, V.M., Gursale, S.C. and Balsara, J.J. (2008) Dose-Dependent Response of Central Dopaminergic Systems to Buspirone in Mice. Indian Journal of Experimental Biology, 46, 704-714.

[13] Cohn, J.B., Rickels, K. and Steege, J.F. (1989) A Pooled, Double-Blind Comparison of the Effects of Buspirone, Diazepam and Placebo in Women with Chronic Anxiety. Current Medical Research and Opinion, 11, 304-320. http://dx.doi.org/10.1185/03007998909115213

[14] Poleszak, E., Wlaź, P., Kêdzierska, E., Nieoczym, D., Wróbel, A., Fidecka, S., Pilc, A. and Nowak, G. (2007) NMDA/ Glutamate Mechanism of Antidepressant-Like Action of Magnesium in Forced Swim Test in Mice. Pharmacology Biochemistry and Behavior, 88, 158-164. http://dx.doi.org/10.1016/j.pbb.2007.07.018

[15] Poleszak, E., Wlaź, P, Wróbel, A., Dybała, M., Sowa, M., Fidecka, S., Pilc, A. and Nowak, G. (2007) Activation of the NMDA/Glutamate Receptor Complex Antagonizes the NMDA Antagonist-Induced Antidepressant-Like Effects in the Forced Swim Test. Pharmacological Reports, 59, 595-600.

[16] Lister, R.G. (1987) The Use of a Plus-Maze to Measure Anxiety in the Mouse. Psychopharmacology, 92, 180-185. http://dx.doi.org/10.1007/BF00177912

[17] Korwar, P.G. and Beknal, A. (2012) Anti-Anxiety Activity of Punica granatum Fruit Juice in Rats. International Journal of Pharmaceutical Invention, 2, 22-30.

[18] Dunn, R.W., Corbett, R. and Fielding, S. (1989) Effects of 5-HT $\mathrm{HA}_{\mathrm{A}}$ Receptor Agonist and NMDA Receptor Antagonist in the Social Interaction Test and the Elevated plus Maze. European Journal of Pharmacology, 169, 1-10. http://dx.doi.org/10.1016/0014-2999(89)90811-X

[19] Poleszak, E. (2008) Benzodiazepine/GABA(A) Receptors Are Involved in Magnesium-Induced Anxiolytic-Like Behavior in Mice. Pharmacological Reports, 60, 483-489. 
Scientific Research Publishing (SCIRP) is one of the largest Open Access journal publishers. It is currently publishing more than 200 open access, online, peer-reviewed journals covering a wide range of academic disciplines. SCIRP serves the worldwide academic communities and contributes to the progress and application of science with its publication.

Other selected journals from SCIRP are listed as below. Submit your manuscript to us via either submit@scirp.org or Online Submission Portal.
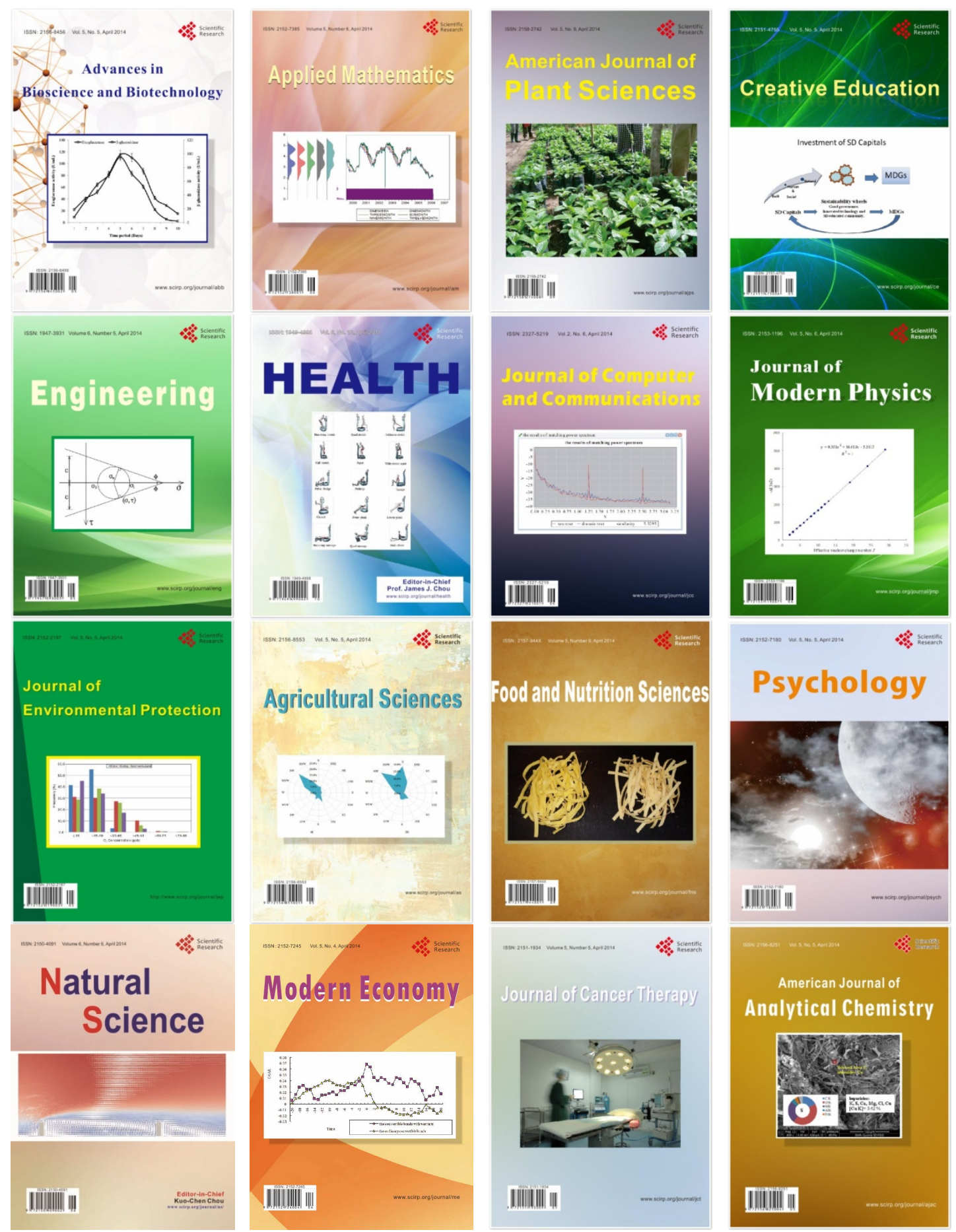